\title{
Peroxisome proliferator-activated receptor- $\gamma$ and its related pathway in bone marrow mesenchymal stem cell differentiation co-cultured with mechanically stretched ligament fibroblasts
}

\author{
BING ZHAO ${ }^{1}$, MENGCAI HU ${ }^{1}$, HUIYAN WU ${ }^{1}$, CHENCHEN REN $^{1}$, JUAN CHEN $^{1}$, \\ XIAODAN ZHANG ${ }^{2}$ and SHIHONG CUI ${ }^{1}$ \\ ${ }^{1}$ The Third Affiliated Hospital of Zhengzhou University; ${ }^{2}$ Zhengzhou Maternal and Child Health Care Hospital, \\ Jinshui, Zhengzhou, Henan 450052, P.R. China
}

Received October 29, 2016; Accepted January 31, 2018

DOI: $10.3892 /$ ijmm.2018.3578

\begin{abstract}
The occurrence of pelvic floor dysfunctional disease (PFD) is closely related with elasticity, toughness, and functional changes of the connective tissue of the pelvic support tissue. Bone marrow mesenchymal stem cells (BMSCs) have been confirmed to have the capacity to differentiate into a variety of cell types such as osteoblasts, chondroblasts, adipocytes and fibroblasts. Therefore, BMSCs have the potential to improve the clinical outcomes for PFD. Peroxisome proliferator-activated receptor- $\gamma$ (PPAR- $\gamma$ ), a ligand activated transcription factor, has acquired a great deal of attention as it is involved in the fibrosis and cell differentiation. However, how it is regulated during the process of the differentiation of BMSCs into fibroblasts remains to be defined. The present study investigated the underlying mechanisms of PPAR- $\gamma$ effect of mechanical stretch on the differentiation of BMSCs induced by pelvic ligament fibroblasts. PPAR- $\gamma$ expression was decreased during the differentiation of BMSCs into fibroblasts by co-cultured stretched fibroblasts. Addition of transforming growth factor- $\beta 1$ (TGF- $\beta 1$ ) reduced PPAR- $\gamma$ expression and promoted the differentiation of BMSCs. With the employment of endogenous ligand, activation of PPAR- $\gamma$ suppressed the BMSC differentiation. Similar effects were also observed with overexpression of PPAR- $\gamma$ gene. In addition, decrease of PPAR $-\gamma$ by the use of shRNA targeting rat PPAR- $\gamma$ significantly contributed to BMSC differentiation to fibroblasts. These results indicate that PPAR $-\gamma$ negatively regulates the differentiation of BMSCs into fibroblasts.
\end{abstract}

Correspondence to: $\mathrm{Dr}$ Shihong Cui, The Third Affiliated Hospital of Zhengzhou University, Zhengzhou, Henan 450052, P.R. China

E-mail: cuishihongchina@gmail.com

Key words: bone marrow stromal cells, stretch, peroxisome proliferator-activated receptor- $\gamma$, differentiation, pelvic ligament fibroblasts

\section{Introduction}

The incidence of pelvic floor dysfunctional disease (PFD) in aging population is increasing because of prolonged life span after menopause $(1,2)$. Older women with PFD have various complications and it affects the quality of life significantly. The occurrence of PFD is closely related with elasticity, toughness, and functional changes of the connective tissue of the pelvic support tissue (3). Normal pelvic structure support and function depend on the pelvic floor connective tissues. It has previously been stated that an alteration in the extracellular matrix proteins of the supporting ligament has been implicated in the PFD (4).

Therapeutic use of mesenchymal stem cells (MSC) is one potential solution, which has already been employed in clinical trials, including the treatment of human myocardial infarction, osteogenesis imperfecta, and graft versus host disease (5). Historically, MSC were first isolated from bone marrow mesenchymal stem cells (BMSCs) (6) and bone marrow is the current gold standard tissue source for therapy. BMSCs come from the mesoderm with multilineage capacity potential and generate a variety of cell types (7), such as osteoblasts, adipocytes, myoblasts, chondrocytes and neurons (8). After injury, endogenous or exogenous BMSCs migrate into lesion for repair. Increasing studies reported that in the process of ligament injury repair, different pluripotent stem cells are released from bone marrow mesenchyme. These stem cells are similar to the surrounding ligament cells, move to and accumulate in the injury sites $(9,10)$. Mesenchymal stem cells also display several anti-inflammatory properties, presenting the possibility for allogenic transplantation (11). However, the underlying regulatory mechanisms for triggering differentiation are only partially understood.

A wound healing reaction is orchestrated by a variety of signals derived from endogenous soluble factors. It is widely accepted that transforming growth factor- $\beta$ (TGF- $\beta$ ) is one of the most critical growth factors regulating cellular responses in the process of wound healing or tissue inflammation (12). TGF- $\beta$ is known as a stimulator for extracellular matrix 
proteins production in fibroblasts and mediates the response of fibroblasts to mechanical stress (13). With the employment of a co-culture system, our previous studies have demonstrated that mechanical stretch could indirectly promote the synthesis of TGF- $\beta$ expression and increase expression of collagen I and II, elastin, LOX, and fibulin-5 during the process of BMSCs differentiation (14). It was also found that TGF- $\beta 1$ and MAPK pathways are involved in the differentiation of BMSCs to pelvic ligament fibroblasts stimulated by mechanic stretch. However, it is still not clearly illustrated whether other molecules are implicated in this process and the underlying mechanisms.

Peroxisome proliferator-activated receptors (PPARs) are ligand-activated transcription factors belonging to the nuclear hormone receptor superfamily. PPARs consist of three members: PPAR- $\alpha,-\beta$ or $-\gamma$, which are involved in modulation of metabolism, immune responses and cell proliferation, i.e., fibrogenic reaction or cell proliferation during wound healing $(15,16)$. It is well known that PPAR- $\gamma$ is mainly related to regulation of adipocyte differentiation and fattyacid uptake and storage (17-20). Previous studies showed that thiazolidinedione, one of PPAR- $\gamma$ synthetic agonists, benefits patients with diabetes type II $(21,22)$. In addition, PPAR- $\gamma$ was found to possess a new action in fibrosis through activation of PPAR- $\gamma$ then reduce fibrosis in several organs, such as heart and lung (23). Furthermore, PPAR- $\gamma$ has been reported to participate in the differentiation of fibroblast $(24,25)$. However, the underlying mechanisms and whether PPAR- $\gamma$ is involved in the regulation of BMSCs differentiation into ligament fibroblasts are still unclear.

Therefore, the present study explored the effects of PPAR- $\gamma$ in BMSC differentiation to ligament fibroblasts. Our data showed that PPAR- $\gamma$ expression was significantly decreased in ligament fibroblasts and in the differentiation of BMSCs to fibroblasts induced by cyclic mechanical stretch in vitro. Additionally, downregulation of PPAR- $\gamma$ by shRNA contributed to the differentiation of BMSCs. Furthermore, upregulation of PPAR $-\gamma$ by natural ligand and PPAR- $\gamma$ overexpression plasmids attenuated BMSCs differentiation to fibroblasts in vitro. The present study suggests that PPAR $-\gamma$ negatively regulates the differentiation of BMSCs in a co-culture system. This will help us to further understand the differentiation potential of BMSCs and characteristics in order to develop a new therapy for pelvic organ prolapse (POP) .

\section{Materials and methods}

Experimental animals. Sprague-Dawley (SD) rats were purchased from Experimental Animal Center of Fourth Military Medical University (Xi'an, China). All studies were conducted in accordance with the standards of humane animal care described in the National Institutes of Health Guide for the Care and Use of Laboratory Animals, using protocols approved by Zhengzhou University Institutional Animal Care and Research Advisory Committee.

Viral production and purification. The lentiviral vector encoding PPAR- $\gamma$ shRNA or control shRNA lentiviral particles was generated by co-transfection of $293 \mathrm{~T}$ cells with the PPAR- $\gamma$-shRNA plasmid vector (sc-156077-V) or the control shRNA Lentiviral Particles (sc-108080) (both from Santa Cruz
Biotechnology, Inc., Santa Cruz, CA, USA). Cell debris was removed through $0.22 \mu \mathrm{m}$ filtration and concentrated by ultracentrifuge at $17,000 \mathrm{rpm}, 4^{\circ} \mathrm{C}$, for $1 \mathrm{~h}$. The bottom pellets containing the lentiviral vector were re-suspended with DMEM medium and diluted to the concentration at $1 \times 10^{8}$ TCID50/ml. The titer was determined by the measurement of the cytosolic p24 protein, 1 pg of p24 reading was assigned as 10 tissue culture infective dosage (TCID50) for freshly isolated lentiviral vectors.

Rat BMSC preparation. Isolation, culture and passage of rat BMSCs from 7-day old SD rats were prepared as previously described (14). Briefly, under sterile conditions, syringe was used to rinse out bone marrow. Then the bone marrow cells were isolated with pre-filled Percoll separation medium. The interface layer of mononuclear cells was flushed two times with cold phosphate-buffered saline (PBS) and maintained in LG-DMEM. These primary cells were subcultured at 80-90\% confluence. BMSCs are characterized by the phenotypes as positive for CD44 and CD90, but negative for CD34 and CD45 in flow cytometry analysis. BMSCs of passage 3 to passage 5 were used in the experiments.

Rat pelvic ligament fibroblasts and fibroblast traction injury model. Rat pelvic ligament fibroblasts were prepared as described and maintained in growth medium. The medium was replaced with fresh medium every other day and the fourth passage of fibroblasts cells was collected for immunohistochemistry staining. Passage 3 fibroblasts $\left(3 \times 10^{5} /\right.$ membrane $)$ were seeded onto gelatin-coated silicone membrane and cultured for $24 \mathrm{~h}$. Then $10 \%$ of the load transformation was exerted on cells with $1 \mathrm{~Hz}$ horizontal stretch stimulation for different duration under $5 \% \mathrm{CO}_{2}$ and $37^{\circ} \mathrm{C}$ conditions. Cells were fixed in paraformaldehyde, and then stained with DAPI $(5 \mu \mathrm{g} / \mathrm{ml})$. Cell morphology was examined under a confocal microscope (Olympus, Tokyo, Japan). BMSCs were seeded into lower chamber while ligament fibroblasts in the upper chamber of 6-well plate. After indirect co-culture for different duration or other treatments, cells were collected for real-time RT-PCR and western blot assay.

Lentiviral transfection of SD rat BMSCs. Confluent BMSCs (70-80\%) of passage 3-5 were collected after digestion and were centrifuged at $168 \mathrm{x}$ g for $5 \mathrm{~min}$. Then the cell pellet was re-suspended and were seeded into a 6-well plate at a density of $1 \times 10^{5}$ cells/well for overnight incubation. Followed by replacement with $1 \mathrm{ml}$ of freshly prepared BMSC complete medium, the cells were then transfected with lentivirus, respectively. Eight hours after the transduction, the BMSC complete medium was replaced and transduction was continued for different duration. After treatment, cells were collected to perform real-time RT-PCR and western blot analysis.

TGF- $\beta 1$ enzyme-linked immunosorbent assay (ELISA). All samples were analyzed for TGF- $\beta 1$ by using a commercially available ELISA kit (R\&D Systems, Minneapolis, MN, USA). Representative samples were tested for the presence of active TGF- $\beta 1$, but the concentration was under the detection limit of the assay. Accordingly, all samples were activated by acidification to separate TGF- $\beta 1$ from its binding proteins, 
allowing for measurement of total TGF- $\beta 1$. For activation of samples containing fetal bovine serum (FBS), $2.5 \mathrm{M}$ acetic acid-10 $\mathrm{M}$ urea were used, and $1 \mathrm{M} \mathrm{HCl}$ was used for microdialysis samples (as recommended by the supplier). Activated samples were neutralized by use of $2.7 \mathrm{M} \mathrm{NaOH}-1 \mathrm{M}$ HEPES for samples with FBS and 1.2 M NaOH-0.5 M HEPES for microdialysis (as recommended by the supplier). Samples were loaded on ELISA plates immediately after neutralization. All samples were measured in duplicate, and samples obtained from each subject were measured in the same assay.

Immunofluorescence and high content screening. BMSCs with or without treatments were fixed in $4 \%$ paraformaldehyde for $30 \mathrm{~min}$. Then cells were rinsed twice with PBS, incubated with $0.5 \%$ Triton $\mathrm{X}-100$ at room temperature for $15 \mathrm{~min}$, blocked with $2 \%$ BSA for $1 \mathrm{~h}$, and incubated overnight with primary antibodies to collagen I (1:200), collagen III (1:200) and PPAR- $\gamma$ (1:250) (all from Santa Cruz Biotechnology, Inc.), followed by secondary antibody conjugated with Cy3 (1:500; Abcam, Shanghai, China) for $1 \mathrm{~h}$. These cells were stained with $10 \mu \mathrm{g} / \mathrm{ml}$ DAPI for $5 \mathrm{~min}$. For negative controls, cells were stained with the same process. The plates were imaged on a Thermo Scientific Cell Insight personal cell imaging (PCI) platform (Cellomics; Thermo Fisher Scientific Inc., Waltham, MA, USA) using the Thermo Scientific Cellomics iDEV software. High content analysis was performed as described previously. Briefly, 3,000 cells in 36 fields were automatically examined by the software. The fluorescence intensity was analyzed using Cellomics Cell Health Profiling BioApplication software.

Real-time PCR. Quantitative RT-PCR was carried out using real-time PCR with the SYBR Green reporter. RNA was isolated using TRIzol RNA extraction kit. OD260 nm was used to determine RNA yield. RNA was subsequently reverse transcribed to cDNA. Three-stage program parameters were provided by the manufacturer as follows: 2 min at $94^{\circ} \mathrm{C}, 30 \mathrm{sec}$ at $60^{\circ} \mathrm{C}$, and $60 \mathrm{sec}$ at $55^{\circ} \mathrm{C}$, then 45 cycles total. Specificity of the produced amplification product was confirmed by examination of dissociation reaction plots. Each sample was tested in triplicate, and samples obtained from three independent experiments were used for analysis of relative gene expression. The following primers for real-time PCR were designed by Takara Co. (Dalian, China): rat PPAR- $\gamma$, forward, 5'-CATTTTTCAAGGGTGCCAGT-3' and reverse, 3'-GAGGCCAGCATGGTGTAGAT-5'; rat glyceraldehyde 3-phosphate dehydrogenase (GAPDH), forward, 5'-CCTTCCGTGTTCCTACCC-3' and reverse, 5'-CAA CCTGGTCCTCAGTGTAG-3'.

Western blot assay. Protein was extracted in $200 \mu \mathrm{l}$ RIPA lysis buffer. Equal amounts of proteins were loaded on $10 \%$ Tris-glycine gels after being denatured. The proteins were then transferred to PVDF membranes. The membranes were blocked with $5 \%$ milk in PBS-T (0.1\% Tween-20), followed by incubation with primary antibodies against PPAR- $\gamma$ and GAPDH at $4{ }^{\circ} \mathrm{C}$ overnight. The membranes were washed with PBS-T and incubated for $1 \mathrm{~h}$ at room temperature with horseradish peroxidase-conjugated secondary antibodies. Following washing, the specific proteins were detected using a chemiluminescent protein detection kit. Each experiment was repeated in triplicate. GAPDH was used as the internal control. The densities of the bands were analyzed using Quantity One (Bio-Rad, Hercules, CA, USA).

Statistical analysis. Data were presented as mean \pm SD. Statistical significance was analyzed by one-way ANOVA using the GraphPad Presim 6.0 software. A value of $\mathrm{P}<0.05$ was considered significant.

\section{Results}

PPAR- $\gamma$ is downregulated in rat ligament fibroblasts and BMSCs after mechanical stretch. Recent studies report that PPAR- $\gamma$ expression is decreased in fibroblasts in in vitro and in vivo studies $(26,27)$. In order to examine PPAR- $\gamma$ expression in fibroblasts and BMSCs after direct mechanical stretch, a custom-made mechanical device was used to apply cyclic uniaxial strains to fibroblasts and BMSCs. Our previous study reported that the expression of collagen type I and III, main ECM proteins, were increased in a dose-dependent manner in both fibroblasts and BMSCs (28). In addition, a similar and significant increase was found in the protein levels of TGF- $\beta 1$ in fibroblasts (Fig. 1A) and BMSCs (Fig. 1B), key growth factors contributing to BMSC differentiation into vascular smooth muscle cells (29), ligament or tendon fibroblast cells (30). These findings of increased TGF- $\beta 1$ and ECM proteins were consistent with other studies $(31,32)$. Furthermore, our results showed that PPAR $-\gamma$ mRNA and protein expression were significantly reduced by mechanical stretch compared with their control groups, respectively (Fig. 1C-F). The expression of PPAR- $\gamma$ was reduced in fibroblast due to mechanical stretch $(33,34)$. Also, the mechanical stretch could inhibit adipocyte differentiation $(35,36)$. Therefore, these results indicated that PPAR- $\gamma$ may play an essential role in the effects of mechanical forces on BMSC differentiation to ligament fibroblasts.

PPAR- $\gamma$ expression reduced by indirect co-culture system with mechanical stretching. The above preliminary data displayed that mechanical stress significantly and directly reduced PPAR- $\gamma$ expression in BMSCs with a time-dependent manner. However, whether indirect co-culture system with mechanically stretched ligament fibroblasts can regulate PPAR- $\gamma$ expression in the BMSCs is uncertain. Therefore, in the present study, indirect co-culture system was employed to determine the PPAR- $\gamma$ expression in BMSCs induced by stretched fibroblasts. With the use of indirect co-culture system, an approximate $26 \%$ decrease of PPAR- $\gamma$ mRNA level in BMSCs was acquired after 3 days of co-culture with mechanical stretched fibroblasts, a $37 \%$ decrease after co-culture for 6 days, and a $68 \%$ decrease after 12 days as compared with the time-point day 0 (Fig. 2A). The data indicate that co-culture with mechanically stretched fibroblasts reduced the PPAR- $\gamma$ expression level in a time-dependent manner. In accordance, immune-fluorescence staining showed that PPAR- $\gamma$ staining degree was weakened in BMSCs after mechanical stimulation for 12 days compared to BMSCs of control group (Fig. 2B).

PPAR- $\gamma$ has negative correlation with collagen type I and III. Increased levels of collagen I and III are indicators of BMSCs differentiation to fibroblasts, because they are 

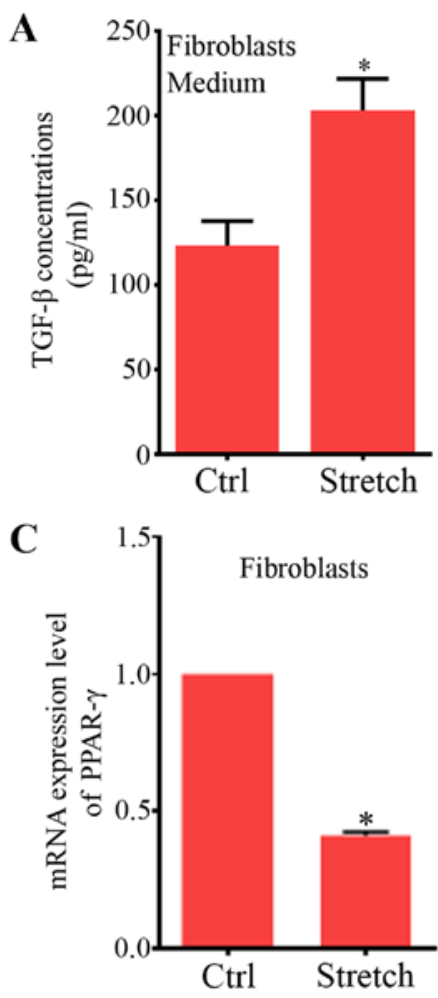

$\mathbf{E}$

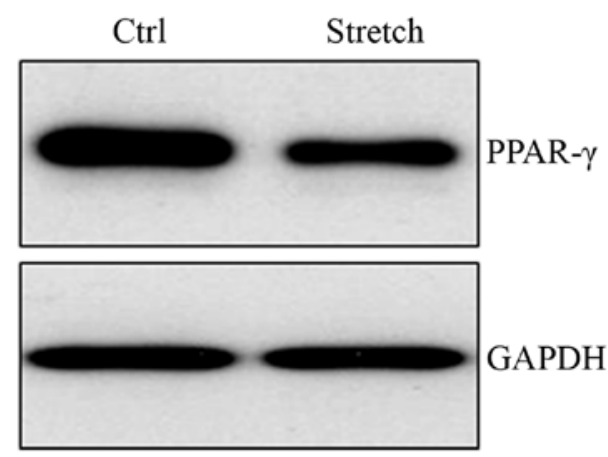

D
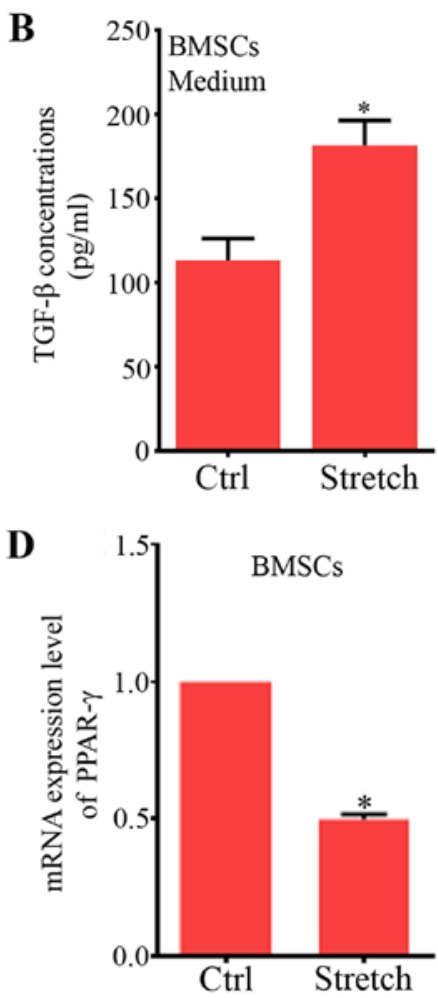

F BMSCs

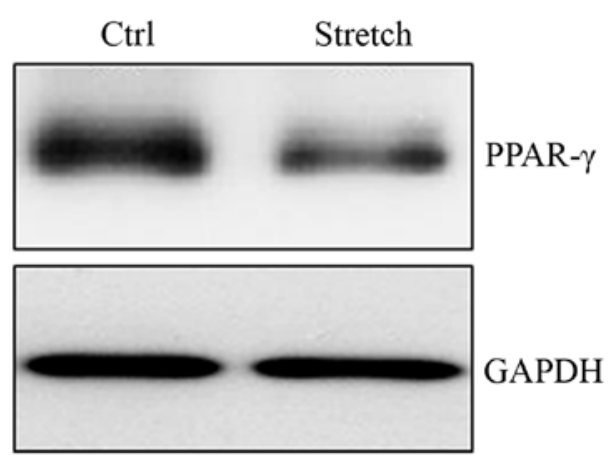

Figure 1. The effect of direct stretch on peroxisome proliferator-activated receptor- $\gamma$ (PPAR- $\gamma$ ) and transforming growth factor- $\beta 1$ (TGF- $\beta 1$ ) expression in fibroblasts and bone marrow mesenchymal stem cells (BMSCs). fibroblasts and BMSCs were cyclically stretched under $10 \%$ stretching at $1 \mathrm{~Hz}$ for $24 \mathrm{~h}$. The supernatant from fibroblasts and BMSCs were collected and tested. (A and B) TGF- $\beta 1$ ELISA analysis of TGF- $\beta 1$ in fibroblasts and BMSCs. (C and D) PPAR- $\gamma$ mRNA expression in fibroblasts and BMSCs. (E and F) PPAR- $\gamma$ expression at protein level in fibroblasts and BMSCs as compared with control groups. ${ }^{*} \mathrm{P}<0.05$ compared with control group.

A

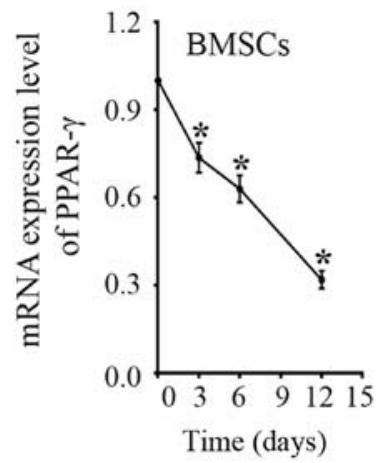

B

Ctrl

Stretch +

Coculture

(day 12)

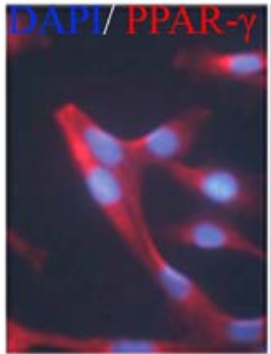

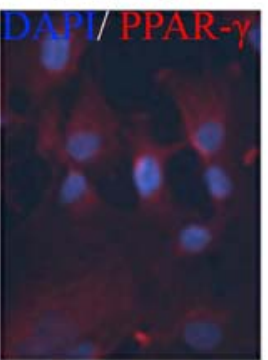

Figure 2. Time course of induction of peroxisome proliferator-activated receptor- $\gamma$ (PPAR- $\gamma$ ) expression in bone marrow mesenchymal stem cells (BMSCs) co-cultured with ligament fibroblasts under $10 \%$ stretching at $1 \mathrm{~Hz}$. (A) BMSCs were co-cultured with ligament fibroblasts which were subjected to mechanical stretch for 0, 3, 6 and 12 days. Total RNA was collected for real-time PCR. ${ }^{*} \mathrm{P}<0.05$ compared with day 0 . (B) Immunofluorescence of PPAR- $\gamma$ in BMSCs after co-culture with ligament fibroblasts without mechanical stretch (control, left), or with mechanical stretch for 12 days (right). 
A

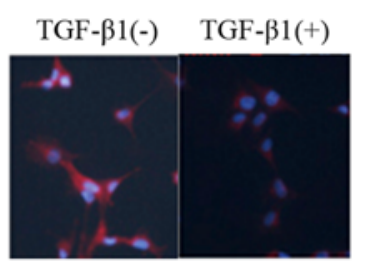

B

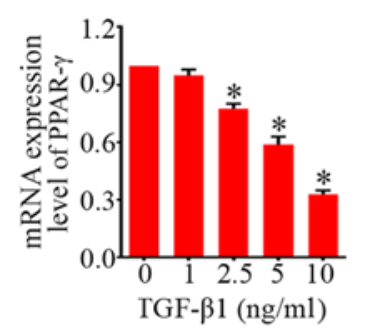

C

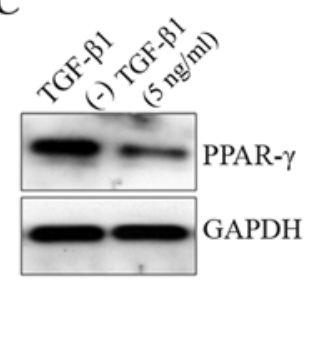

D

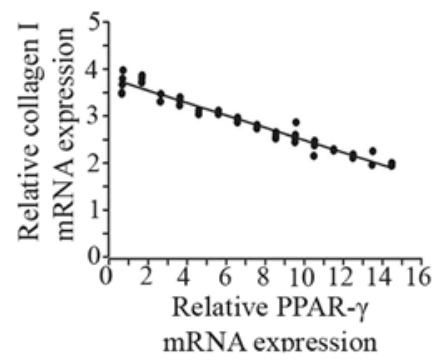

$\mathbf{E}$

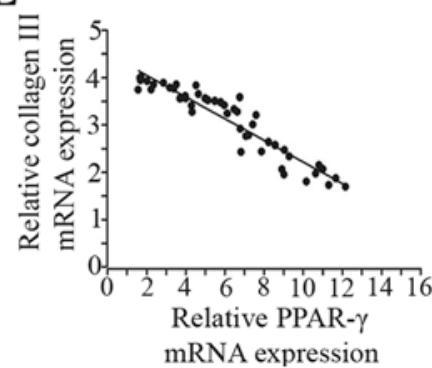

Figure 3. Peroxisome proliferator-activated receptor- $\gamma$ (PPAR- $\gamma$ ) is involved in the differentiation of bone marrow mesenchymal stem cells (BMSCs) to ligament fibroblasts. (A) Immunofluorescence of PPAR- $\gamma$ in BMSCs without addition of transforming growth factor- $\beta 1$ (TGF- $\beta 1)(-)$ and with addition of TGF- $\beta 1(+)$. (B) PPAR- $\gamma$ mRNA expression in BMSCs induced by TGF- $\beta 1$ in a dose-dependent manner. (C) PPAR- $\gamma$ protein expression in BMSCs after addition of TGF- $\beta 1$ at $5 \mathrm{ng} / \mathrm{ml}$. Correlations between PPAR- $\gamma$ mRNA expression and (D) collagen I or (E) collagen III. *P<0.05 compared with control group.

usually described as the common characteristics of ligament fibroblasts (37). Given that PPAR- $\gamma$ had negative correlation with these collagen type I and III, we then explored the function of PPAR- $\gamma$ in the differentiation of BMSCs. Here, we employed immunostaining to examine PPAR- $\gamma$ expression in the process of BMSC differentiation to ligament fibroblasts. The results of immunofluorescence staining showed that the degree of PPAR- $\gamma$ staining was much weaker in the BMSC differentiation induced by TGF- $\beta 1$ only as compared with control group (Fig. 3A). Furthermore, the PPAR- $\gamma$ mRNA level was dramatically reduced during differentiation process activated by TGF- $\beta 1$ in a dose-dependent manner (Fig. 3B). The protein expression of PPAR- $\gamma$ was also decreased (Fig. 3C). Additionally, the data showed that there were negative relationships between PPAR $-\gamma$ mRNA expression and collagen I or III in BMSCs (Fig. 3D and E). These findings uncover the roles of PPAR- $\gamma$ in the differentiation of BMSCs to ligament fibroblasts.

Synergistic effects of TGF- $\beta 1$ and indirect co-culture with mechanically stretched fibroblasts on PPAR- $\gamma$ expression. To study whether growth factor and co-culture with strained fibroblasts are synergistic, we investigated their effects on the PPAR- $\gamma$ mRNA expression in BMSCs. TGF- $\beta 1$ is a paracrine growth factor-mediating cell response to mechanical strain. This factor then downregulates PPAR- $\gamma$ mRNA expression in fibroblasts (38). Our above data showed that direct mechanical stretch significantly increased TGF- $\beta 1$ expression in fibroblasts and BMSCs (Fig. 1A and B). Therefore, we hypothesized that mechanical stretch signal indirectly reduced PPAR- $\gamma$ expression in BMSCs mediated via TGF- $\beta 1$, released from strained fibroblasts an addition of exogenous factor should synergistically increase the effects of mechanical stretch on the PPAR- $\gamma$ expression. As shown in Fig. 4A, without addition of TGF- $\beta 1$, the expression level of PPAR- $\gamma$ was reduced by indirect mechanical stimulation to $\sim 63 \%$ less than control group. As shown in the above (Fig. 4A), addition of TGF- $\beta 1$ at $5 \mathrm{ng} / \mathrm{ml}$ significantly decreased PPAR- $\gamma$ expression levels as compared to those without TGF- $\beta 1$ treatment. With the application of indirect mechanical stretch, an extra PPAR- $\gamma$ expression level decrease was acquired after addition of TGF- $\beta 1$ (Fig. 4B). These results indicated that the effect of growth factor and indirect co-culture with strained fibroblasts appeared to be synergistic on the induction of PPAR- $\gamma$ expression in BMSCs.

PPAR $-\gamma$ negatively modulates the differentiation of BMSCs toward fibroblasts induced by indirect cocultred with stretched fibroblasts. Upregulation of collagen I and III is an essential characteristic during BMSC differentiation to fibroblasts. Therefore, to further seek the characteristic effects of PPAR- $\gamma$ on the expression of collagen I and III in BMSC differentiation, we employed endogenous ligand (15d-PGJ2) and PPAR- $\gamma$ overexpression plasmids. As showed in Fig. 5A and B, endogenous ligand and overexpression plasmids were able to attenuate the increases of collagen I and III mRNA expression in BMSCs treated with indirect mechanical stretch. Transfection of BMSCs with PPAR- $\gamma$ shRNA decreased the mRNA expression of PPAR- $\gamma$ around $75 \%$ (Fig. 5F). Furthermore, western blot analysis showed that PPAR- $\gamma$ protein was also significantly reduced (Fig. 5G). The real-time PCR showed that PPAR- $\gamma$ shRNA increased collagen I and III mRNA expression as compared with scrambled control plasmids (Fig. 5H and I).

To further confirm the effects of PPAR- $\gamma$ in BMSC differentiation, we employed immunohistochemistry staining for collagen I and III to determine morphological changes in BMSCs. As shown in Fig. 5E, the BMSCs without treatment displayed very weak expression of collagen I and III. Indirect mechanical stretch treatment stimulated formation of thick 


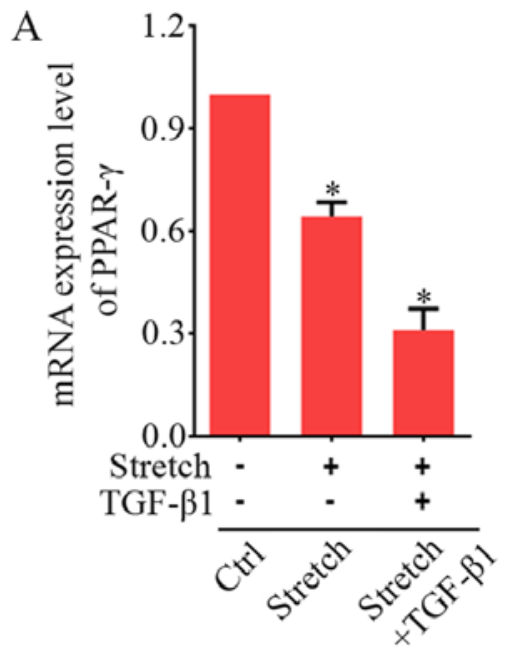

B

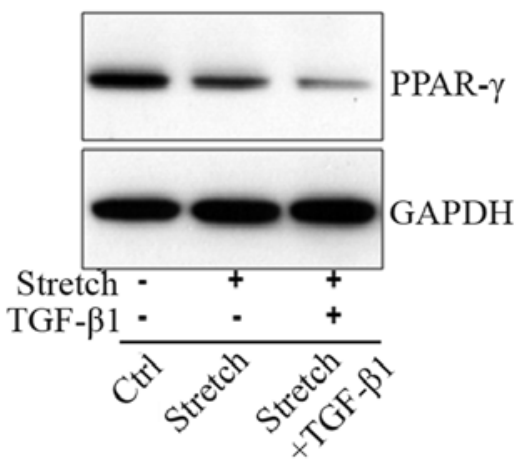

Figure 4. Synergistic effect of growth factor transforming growth factor- $\beta 1$ (TGF- $\beta 1$ ) with indirect mechanical stretch on the peroxisome proliferator-activated receptor- $\gamma$ (PPAR- $\gamma$ ) mRNA expression. In two separate experiments, bone marrow mesenchymal stem cells (BMSCs) were incubated without or with TGF- $\beta 1$ at $5 \mathrm{ng} / \mathrm{ml}$. These cells were also co-cultured with ligament fibroblasts subject to stretch or no stretch as control. Cells were collected and subjected to (A) real-time PCR and (B) western blotting as shown above. ${ }^{*} \mathrm{P}<0.05$ compared with control group.
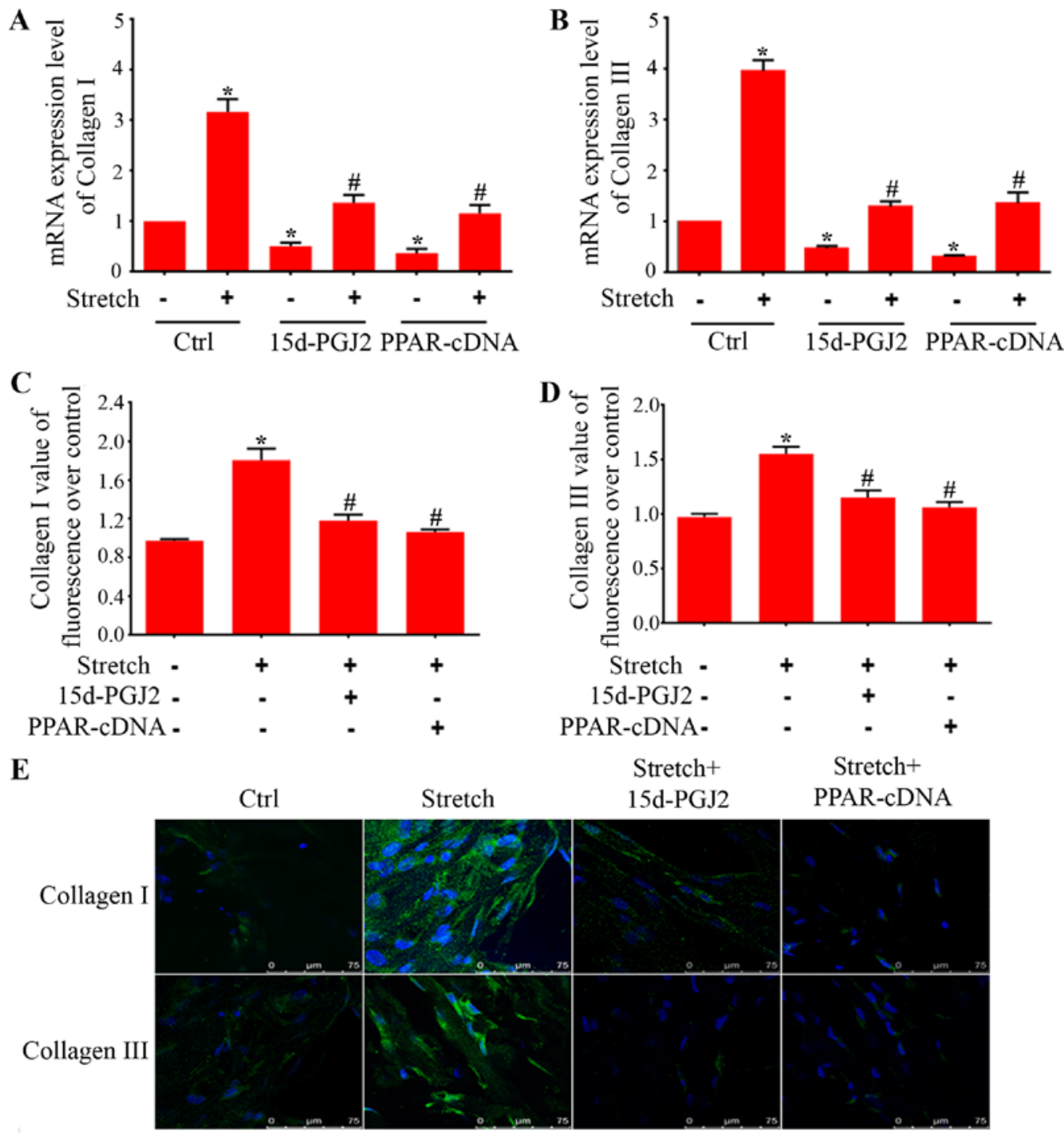

Figure 5. Peroxisome proliferator-activated receptor- $\gamma(\operatorname{PPAR}-\gamma)$ negatively regulates collagen I and collagen III expression in bone marrow mesenchymal stem cells (BMSCs). BMSCs were incubated with 15d-PGJ2 at $6 \mu \mathrm{mol} / 1$, or transfected with PPAR- $\gamma$ overexpression plasmids, then these cells were co-cultured with ligament fibroblasts with stretch or without stretch as control. Collagen I and collagen III were subjected to (A and B) real-time PCR, (C and D) high content screening and (E) immunofluorescence. 
F

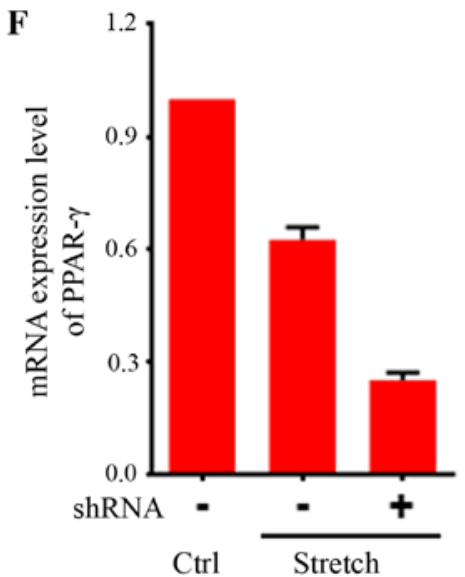

H

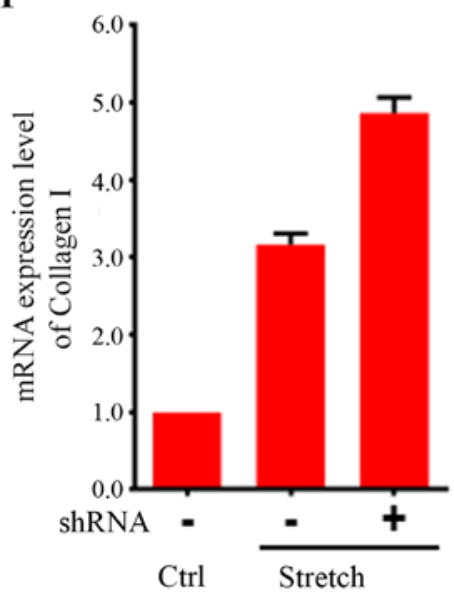

G

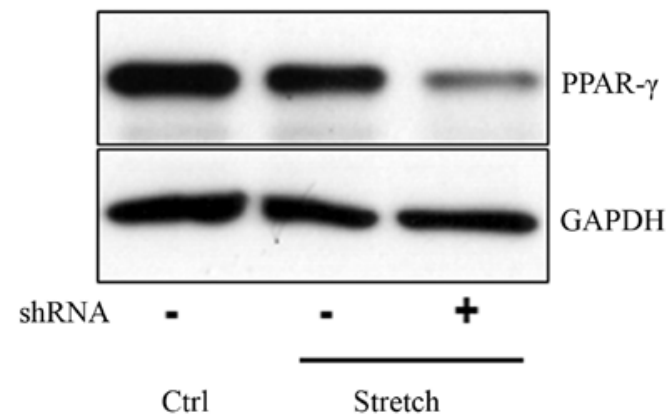

I

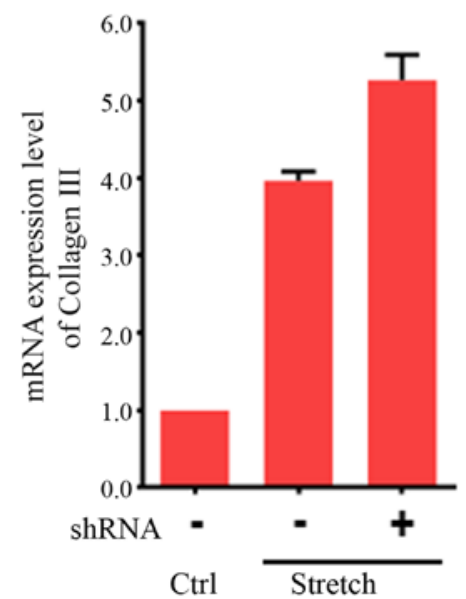

Figure 5. Continued. After transfected with PPAR- $\gamma$ shRNA and/or indirect stretch, BMSCs were collected for determination of (F and G) PPAR- $\gamma$ expression, ( $\mathrm{H}$ and I) collagen I and collagen III mRNA expression. ${ }^{*} \mathrm{P}<0.05$ compared with control group; ${ }^{~} \mathrm{P}<0.05$ compared with stretched co-cultured group.

bundles of actin filaments and dramatically increased the expression of collagen I and III in BMSCs. However, treatment with ligand of PPAR- $\gamma$ and overexpression plasmid markedly attenuated collagen I and III expression in BMSCs induced after exposure to indirect mechanical stretch. In addition, our immunostaining assay showed that treatment with $15 \mathrm{~d}-\mathrm{PGJ} 2$ and PPAR- $\gamma$ expression plasmids reduced ECM protein levels of collagen I (Fig. 5C) and collagen III (Fig. 5D) in differentiated BMSCs triggered by mechanical forces.

\section{Discussion}

PFD is a distressing morbidity that affects the quality of women's life in developed and developing countries (39). Pelvic organ support is maintained by complex interactions between levator ani muscles and connective tissues of the urethra, vaginal wall and rectum. Major ani muscle defects is a key factor of POP (40). In the past decade, the field of stem cell biology has undergone a remarkable evolution. Stem cells have a great potential to develop into many different specialized cells in the body. There is increasing evidence suggesting that BMSCs can be used as a new revolutionary cell-based therapy to repair ligament, tendon and cartilage (41).

Differentiation of BMSCs toward fibroblasts is an essential event for ligament tissue engineering. Our previous study reported that the BMSCs with positive expression of CD90 and CD44 differentiate towards fibroblast triggered by indirect co-culture with stretched ligament fibroblasts. Indirect mechanical stretch also changes cell morphology and stimulates expression of collagen I and II, elastin, Lox and fibulin-5 in BMSCs (42). However, further studies needed to be performed to explore the underlying mechanisms. In the present study, we explored the potential role of PPAR- $\gamma$ in the differentiation of primary rat BMSCs to fibroblasts. We found PPAR $-\gamma$ negatively regulated BMSC differentiation toward fibroblasts. It has been reported that expression of PPAR- $\gamma$ was reduced in fibroblasts (33). Differentiation of BMSCs was accompanied by the decrease of PPAR- $\gamma$ expression. Activated PPAR- $\gamma$ by specific ligands were able to attenuate BMSC differentiation in vitro. These results critically revealed a mechanism underlying differentiation of BMSCs toward fibroblasts.

There is accumulating evidence demonstrating that PPAR- $\gamma$ expression was significantly decreased in the fibroblasts during the formation of fibrosis (43). However, activation of PPAR- $\gamma$ has the capacity to reduce the fibrosis (43). In this study, the expression levels of PPAR- $\gamma$ were dramatically reduced in BMSCs during differentiation to fibroblasts, similar to the report that PPAR- $\gamma$ expression was downregulated in the differentiation of bone marrow-derived mesenchymal stem cells into myofibroblasts (34). Additionally, the relationships between the mRNA expression level of PPAR- $\gamma$ and other 
ECM proteins, such as collagen I and III, were negative, which are similar to a report by other researchers (44). Furthermore, PPAR- $\gamma$ was negatively regulated by TGF- $\beta 1$, which can mediate fibrosis (45). These results indicate that PPAR- $\gamma$ may play an important role in BMSC differentiation to fibroblasts.

Previous studies reported that PPAR- $\gamma$ was significantly decreased in the differentiation of various fibroblasts (38). In the present study, the expression level of PPAR- $\gamma$ was significantly downregulated in BMSC differentiation toward fibroblasts induced by TGF- $\beta 1$ only and indirect co-culture with strained fibroblasts. In addition, the downregulation of PPAR- $\gamma$ by specific shRNA had the capacity of promoting the differentiation of BMSCs. BMSCs retain their growth potential and multipotency to differentiate toward a variety of mesenchymal cells, such as fibroblasts and adipocytes (46). Therefore, it was hypothesized that in our study the downregulated expression of PPAR $-\gamma$ related to fat-formation may contribute to the differentiation of BMSCs to fibroblasts because of the decreased potential to differentiate to adipocytes. Previous study reported that PPAR- $\gamma$ expression could be decreased by TGF- $\beta 1$ via smad binding with the PPAR- $\gamma$ gene promoter to reduce the promoter activity of PPAR- $\gamma$ gene or through increasing the binding of histone deacetylase 1 (HDAC1) and decreasing the levels of acetylated histone $3(\mathrm{AcH} 3)$ at the PPAR- $\gamma$ promoter $(25,38)$. However, the detailed underlying mechanisms of PPAR- $\gamma$ expression involved in the BMSC differentiation to fibroblasts is still unclear and should be explored in further study.

The effects of PPAR- $\gamma$ require prior activation by ligands. In this study, our data showed that natural endogenous ligand of PPAR- $\gamma$ was able to inhibit BMSC differentiation to fibroblasts induced by TGF- $\beta 1$ and indirect co-culture in vitro. Moreover, this natural ligand also attenuate expression of collagen type I and III. Therefore, these results evidently support that PPAR- $\gamma$ is significantly downregulated in the process of BMSC differentiation to fibroblasts. Our previous result indicated that TGF- $\beta 1$ and MAPK/ERK pathway participates in the differentiation of BMSCs to fibroblasts. In the present study, PPAR- $\gamma$ negatively regulates BMSC differentiation to fibroblasts. There are several studies demonstrating that PPAR- $\gamma$ is involved in TGF- $\beta 1 /$ Smad and MAPK signaling pathway (47-49). Recent studies have reported that the PPAR- $\gamma$ agonist was able to activate PPAR- $\gamma$ to regulate ECM protein expression through targeting the TGF- $\beta 1 /$ Smad3 and MAPK signaling pathways $(49,50)$. Therefore, the PPAR- $\gamma$, TGF- $\beta 1 /$ Smad and MAPK signaling pathways may play important roles in transcriptional regulation of collagen and expression of other ECM proteins in the process of BMSC differentiation to fibroblasts.

In conclusion, our results demonstrate that PPAR- $\gamma$ negatively regulate differentiation of BMSC to fibroblasts in vitro. Downregulation of PPAR- $\gamma$ expression occurs in the differentiation of BMSCs to fibroblasts, and increase of PPAR- $\gamma$ by agonists restrains BMSC differentiation in vitro. However, this study suggests investigation of these molecular mechanisms underlying the effects of PPAR- $\gamma$ on BMSC differentiation to fibroblasts are warranted.

\section{Acknowledgements}

We would like to thank all the other staff in the Laboratory Animal Center of Zhengzhou University for their assistance in the experiments.

\section{Funding}

This study was supported by the National Natural Science Foundation of China (award no. 81300469) and the Key Technology Research and Development Program Foundation of Henan Provincial Health Bureau (award no. 201303093).

\section{Availability of data and material}

The datasets generated and/or analyzed during the current study are not publicly available due to patent application and collaboration with a third party for potential clinical use. Restrictions apply to the availability of these data. However, the data are available from the corresponding author on reasonable request and with the permission from the lawyer.

\section{Authors' contributions}

$\mathrm{SC}$ and BZ participated in the study conception and design. $\mathrm{BZ}, \mathrm{MH}, \mathrm{HW}, \mathrm{CR}, \mathrm{JC}$, and $\mathrm{XZ}$ acquired the data. BZ and $\mathrm{MH}$ analyzed the data. BZ drafted the manuscript. SC made critical revisions. All authors read and approved the final manuscript.

\section{Ethics approval and consent to participate}

All studies were conducted in accordance with the standards of humane animal care described in the National Institutes of Health Guide for the Care and Use of Laboratory Animals, using protocols approved by Zhengzhou University Institutional Animal Care and Research Advisory Committee.

\section{Consent for publication}

Not applicable.

\section{Competing interests}

The authors declare that they have no competing interests.

\section{References}

1. Choi KH and Hong JY: Management of pelvic organ prolapse. Korean J Urol 55: 693-702, 2014

2. Giarenis I and Robinson D: Prevention and management of pelvic organ prolapse. F1000Prime Rep 6: 77, 2014.

3. Wiegersma M, Panman CM, Kollen BJ, Berger MY, Lisman-Van Leeuwen Y and Dekker JH: Effect of pelvic floor muscle training compared with watchful waiting in older women with symptomatic mild pelvic organ prolapse: Randomised controlled trial in primary care. BMJ 349: g7378, 2014.

4. Aznal SS, Meng FG, Nalliah S, Tay A, Chinniah K and Jamli MF: Biochemical evaluation of the supporting structure of pelvic organs in selected numbers of premenopausal and postmenopausal Malaysian women. Indian J Pathol Microbiol 55: 450-455, 2012.

5. Wei X, Yang X, Han ZP, Qu FF, Shao L and Shi YF: Mesenchymal stem cells: A new trend for cell therapy. Acta Pharmacol Sin 34: 747-754, 2013.

6. Via AG, Frizziero A and Oliva F: Biological properties of mesenchymal stem cells from different sources. Muscles Ligaments Tendons J 2: 154-162, 2012.

7. Pelosi E, Castelli G and Testa U: Human umbilical cord is a unique and safe source of various types of stem cells suitable for treatment of hematological diseases and for regenerative medicine. Blood Cells Mol Dis 49: 20-28, 2012.

8. Marion NW and Mao JJ: Mesenchymal stem cells and tissue engineering. Methods Enzymol 420: 339-361, 2006.

9. Miller MD, Nichols T and Butler CA: Patella fracture and proximal patellar tendon rupture following arthroscopic anterior cruciate ligament reconstruction. Arthroscopy 15: 640-643, 1999. 
10. Omoto M, Miyashita H, Shimmura S, Higa K, Kawakita T, Yoshida S, McGrogan M, Shimazaki J and Tsubota K: The use of human mesenchymal stem cell-derived feeder cells for the cultivation of transplantable epithelial sheets. Invest Ophthalmol Vis Sci 50: 2109-2115, 2009.

11. Li J, Lu S, Yang S, Xing W, Feng J, Li W, Zhao Q, Wu H, Ge M, Ma F, et al: Impaired immunomodulatory ability of bone marrow mesenchymal stem cells on CD4(+) T cells in aplastic anemia. Results Immunol 2: 142-147, 2012

12. Pakyari M, Farrokhi A, Maharlooei MK and Ghahary A: Critical role of transforming growth factor beta in different phases of wound healing. Adv Wound Care (New Rochelle) 2: 215-224, 2013.

13. Horiguchi M, Ota M and Rifkin DB: Matrix control of transforming growth factor- $\beta$ function. J Biochem 152: 321-329, 2012

14. Bing Z, Linlin L, Jianguo Y, Shenshen R, Ruifang R and Xi Z: Effect of mechanical stretch on the expressions of elastin, LOX and Fibulin-5 in rat BMSCs with ligament fibroblasts co-culture. Mol Biol Rep 39: 6077-6085, 2012.

15. Evans RM: The steroid and thyroid hormone receptor superfamily. Science 240: 889-895, 1988

16. Kota BP,Huang TH and Roufogalis BD: An overview on biological mechanisms of PPARs. Pharmacol Res 51: 85-94, 2005.

17. Knouff $\mathrm{C}$ and Auwerx J: Peroxisome proliferator-activated receptor-gamma calls for activation in moderation: Lessons from genetics and pharmacology. Endocr Rev 25: 899-918, 2004.

18. Lehrke M and Lazar MA: The many faces of PPARgamma Cell 123: 993-999, 2005.

19. Szanto A and Nagy L: The many faces of PPARgamma: Antiinflammatory by any means? Immunobiology 213: 789-803, 2008

20. Rosen ED and Spiegelman BM: PPARgamma: A nuclear regulator of metabolism, differentiation, and cell growth. J Biol Chem 276: 37731-37734, 2001.

21. Imano E, Kanda T, Nakatani Y, Nishida T, Arai K, Motomura M Kajimoto Y, Yamasaki Y and Hori M: Effect of troglitazone on microalbuminuria in patients with incipient diabetic nephropathy Diabetes Care 21: 2135-2139, 1998.

22. Bakris GL, Ruilope LM, McMorn SO, Weston WM, Heise MA, Freed MI and Porter LE: Rosiglitazone reduces microalbuminuria and blood pressure independently of glycemia in type 2 diabetes patients with microalbuminuria. J Hypertens 24 2047-2055, 2006.

23. Deng YL, Xiong XZ and Cheng NS: Organ fibrosis inhibited by blocking transforming growth factor- $\beta$ signaling via peroxisome proliferator-activated receptor $\gamma$ agonists. Hepatobiliary Pancreat Dis Int 11: 467-478, 2012

24. Gonzalez EG, Selvi E, Balistreri E, Akhmetshina A, Palumbo K, Lorenzini S, Lazzerini PE, Montilli C, Capecchi PL, Lucattelli M, et al: Synthetic cannabinoid ajulemic acid exerts potent antifibrotic effects in experimental models of systemic sclerosis. Ann Rheum Dis 71: 1545-1551, 2012.

25. Zheng S and Chen A: Disruption of transforming growth factor-beta signaling by curcumin induces gene expression of peroxisome proliferator-activated receptor-gamma in rat hepatic stellate cells. Am J Physiol Gastrointest Liver Physiol 292: G113-G123, 2007.

26. Ibarra-Lara ML, Sánchez-Aguilar M, Soria E, Torres-Narváez JC Del Valle-Mondragón L, Cervantes-Pérez LG, Pérez-Severiano F, Ramírez-Ortega MC, Pastelín-Hernández G, Oidor-Chan VH, et al: Peroxisome proliferator-activated receptors (PPAR) downregulate the expression of pro-inflammatory molecules in an experimental model of myocardial infarction. Can J Physiol Pharmacol 94: 634-642, 2016.

27. Ravingerová T, Adameová A, Kelly T, Antonopoulou E, Pancza D, Ondrejcáková M, Khandelwal VK, Carnická S and Lazou A: Changes in PPAR gene expression and myocardial tolerance to ischaemia: Relevance to pleiotropic effects of statins Can J Physiol Pharmacol 87: 1028-1036, 2009.

28. Ren CC, Ren RF, Zhao B, Zhang X and Jiang YJ: Study on oriented differentiation of bone marrow mesenchymal stem cells by fibroblast in rat uterine ligament with mechanical stretch. Zhonghua Fu Chan Ke Za Zhi 46: 527-532, 2011 (In Chinese).

29. Guo $X$ and Chen SY: Transforming growth factor- $\beta$ and smooth muscle differentiation. World J Biol Chem 3: 41-52, 2012.

30. Sahoo S, Ang LT, Cho-Hong Goh J and Toh SL: Bioactive nanofibers for fibroblastic differentiation of mesenchymal precursor cells for ligament/tendon tissue engineering applications. Differentiation 79: 102-110, 2010.

31. Gutierrez JA and Perr HA: Mechanical stretch modulates TGF-beta1 and alpha1(I) collagen expression in fetal human intestinal smooth muscle cells. Am J Physiol 277: G1074-G1080, 1999.
32. Lindahl GE, Chambers RC, Papakrivopoulou J, Dawson SJ, Jacobsen MC, Bishop JE and Laurent GJ: Activation of fibroblast procollagen alpha 1(I) transcription by mechanical strain is transforming growth factor-beta-dependent and involves increased binding of CCAAT-binding factor (CBF/NF-Y) at the proximal promoter. J Biol Chem 277: 6153-6161, 2002

33. David V, Martin A, Lafage-Proust MH, Malaval L, Peyroche S, Jones DB, Vico L and Guignandon A: Mechanical loading downregulates peroxisome proliferator-activated receptor gamma in bone marrow stromal cells and favors osteoblastogenesis at the expense of adipogenesis. Endocrinology 148: 2553-2562, 2007.

34. Jia S, Liu X, Li W, Xie J, Yang L and Li L: Peroxisome proliferator-activated receptor gamma negatively regulates the differentiation of bone marrow-derived mesenchymal stem cells toward myofibroblasts in liver fibrogenesis. Cell Physiol Biochem 37: 2085-2100, 2015.

35. Tanabe Y, Koga M, Saito M, Matsunaga Y and Nakayama K: Inhibition of adipocyte differentiation by mechanical stretching through ERK-mediated downregulation of PPARgamma2. J Cell Sci 117: 3605-3614, 2004.

36. Tanabe $\mathrm{Y}$ and Nakayama K: Mechanical stretching inhibits adipocyte differentiation of 3T3-L1 cells: The molecular mechanism and pharmacological regulation. Nihon Yakurigaku Zasshi 124: 337-344, 2004 (In Japanese).

37. Takayama S, Murakami S, Miki Y, Ikezawa K, Tasaka S, Terashima A, Asano T and Okada H: Effects of basic fibroblast growth factor on human periodontal ligament cells. J Periodontal Res 32: 667-675, 1997.

38. Gong K, Chen YF, Li P, Lucas JA, Hage FG, Yang Q, Nozell SE, Oparil S and Xing D: Transforming growth factor- $\beta$ inhibits myocardial PPAR $\gamma$ expression in pressure overload-induced cardiac fibrosis and remodeling in mice. J Hypertens 29: 1810-1819, 2011.

39. Ewies AA, Al-Azzawi Fand Thompson J: Changes in extracellular matrix proteins in the cardinal ligaments of post-menopausal women with or without prolapse: A computerized immunohistomorphometric analysis. Hum Reprod 18: 2189-2195, 2003.

40. Boreham MK, Wai CY, Miller RT, Schaffer JI and Word RA: Morphometric properties of the posterior vaginal wall in women with pelvic organ prolapse. Am J Obstet Gynecol 187: 1501-1509, 2002 .

41. Kon E, Filardo G, Roffi A, Andriolo L and Marcacci M: New trends for knee cartilage regeneration: From cell-free scaffolds to mesenchymal stem cells. Curr Rev Musculoskelet Med 5: 236-243, 2012.

42. Lee IC, Wang JH, Lee YT and Young TH: The differentiation of mesenchymal stem cells by mechanical stress or/and co-culture system. Biochem Biophys Res Commun 352: 147-152, 2007.

43. Meng Z, Yu XH, Chen J, Li L and Li S: Curcumin attenuates cardiac fibrosis in spontaneously hypertensive rats through PPAR- $\gamma$ activation. Acta Pharmacol Sin 35: 1247-1256, 2014.

44. Miyahara T, Schrum L, Rippe R, Xiong S, Yee HF Jr, Motomura K, Anania FA, Willson TM and Tsukamoto $\mathrm{H}$ : Peroxisome proliferator-activated receptors and hepatic stellate cell activation. J Biol Chem 275: 35715-35722, 2000

45. Wei J, Ghosh AK, Sargent JL, Komura K, Wu M, Huang QQ, Jain M, Whitfield ML, Feghali-Bostwick C and Varga J: PPAR $\gamma$ downregulation by TGFB in fibroblast and impaired expression and function in systemic sclerosis: A novel mechanism for progressive fibrogenesis. PLoS One 5: e13778, 2010.

46. Pittenger MF, Mackay AM, Beck SC, Jaiswal RK, Douglas R, Mosca JD, Moorman MA, Simonetti DW, Craig S and Marshak DR: Multilineage potential of adult human mesenchymal stem cells. Science 284: 143-147, 1999.

47. Tontonoz P, Hu E, Graves RA, Budavari AI and Spiegelman BM: mPPAR gamma 2: Tissue-specific regulator of an adipocyte enhancer. Genes Dev 8: 1224-1234, 1994.

48. Jeon KI, Kulkarni A, Woeller CF, Phipps RP, Sime PJ, Hindman HB and Huxlin KR: Inhibitory effects of PPAR ligands on TGF- $\beta 1$-induced corneal myofibroblast transformation. Am J Pathol 184: 1429-1445, 2014.

49. Guo B, Koya D, Isono M, Sugimoto T, Kashiwagi A and Haneda M: Peroxisome proliferator-activated receptor-gamma ligands inhibit TGF-beta 1-induced fibronectin expression in glomerular mesangial cells. Diabetes 53: 200-208, 2004.

50. Liu Y, Dai B, Xu C, Fu L, Hua Z and Mei C: Rosiglitazone inhibits transforming growth factor- $\beta 1$ mediated fibrogenesis in ADPKD cyst-lining epithelial cells. PLoS One 6: e28915, 2011.

This work is licensed under a Creative Commons Attribution-NonCommercial-NoDerivatives 4.0 International (CC BY-NC-ND 4.0) License. 